This item was submitted to Loughborough's Research Repository by the author.

Items in Figshare are protected by copyright, with all rights reserved, unless otherwise indicated.

\title{
Synthesis of the pyoverdin chromophore by a biomimetic oxidative cyclization
}

PLEASE CITE THE PUBLISHED VERSION

http://dx.doi.org/10.1021/ol802804c

PUBLISHER

(C) American Chemical Society

VERSION

AM (Accepted Manuscript)

\section{PUBLISHER STATEMENT}

This work is made available according to the conditions of the Creative Commons Attribution-NonCommercialNoDerivatives 4.0 International (CC BY-NC-ND 4.0) licence. Full details of this licence are available at: https://creativecommons.org/licenses/by-nc-nd/4.0/

\section{LICENCE}

CC BY-NC-ND 4.0

\section{REPOSITORY RECORD}

Jones, Raymond C.F., Sze-Chak Yau, James N. Iley, Janet E. Smith, James Dickson, Mark R.J. Elsegood, Vickie Mckee, and Simon J. Coles. 2019. "Synthesis of the Pyoverdin Chromophore by a Biomimetic Oxidative Cyclization”. figshare. https://hdl.handle.net/2134/15712. 


\title{
Synthesis of the Pyoverdin Chromophore by a Biomimetic Oxidative Cyclisation
}

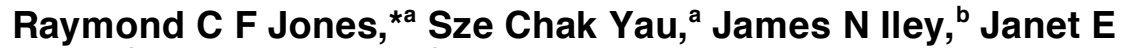 \\ Smith, ${ }^{\text {b }}$ James Dickson ${ }^{\mathrm{b}}$, Mark R J Elsegood, ${ }^{a}$ Vickie McKee $^{\mathrm{a}}$ and \\ Simon J Coles ${ }^{\mathrm{c}}$
}

${ }^{a}$ Chemistry Dept., Loughborough University, Loughborough, Leics. LE11 3TU, UK,

${ }^{b}$ Chemistry Dept., Open University, Walton Hall, Milton Keynes MK7 6AA, UK, and

${ }^{c}$ EPSRC National Crystallography Service, School of Chemistry, University of

Southampton, Highfield, Southampton SO17 1BJ, UK

r.c.f.jones@lboro.ac.uk

Received Date (will be automatically inserted after manuscript is accepted)

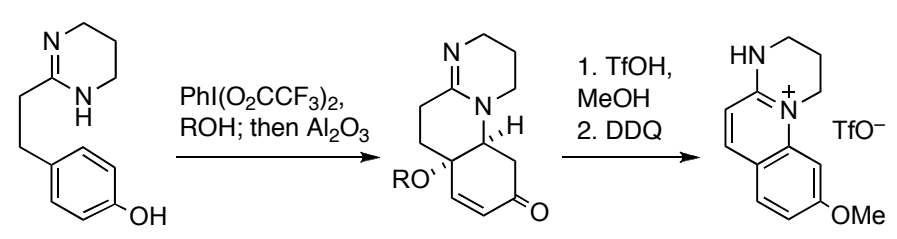

The fluorescent dihydropyrimido[1,2-a]quinoline chromophore of the pyoverdin siderophores has been synthesized by a biomimetic oxidative cyclisation using an iodine(III) reagent, followed by elimination and dehydrogenation.

The pyoverdins are siderophores secreted by fluorescent Pseudomonas sp. including the pathogenic $P$. aeruginosa under conditions of iron starvation. ${ }^{1}$ Structurally they comprise a species-specific peptide of 6-19 residues containing D-amino acids and hydroxamates, and a characteristic 2,3-dihydro-1 $H$-pyrimido[1,2-a]quinoline chromophore, as exemplified by pyoverdin Pf CCM2798 1 from $P$. fluorescens (Figure 1). ${ }^{2} \quad$ This example also illustrates the occurrence of the tetrahydropyrimidine amino acid unit in some pyoverdins. Our interest in cyclic amidine amino acids as dipeptide mimics $^{3}$ led us to prepare some tetrahydropyrimidine pseudodipeptides 2 related to pyoverdins (Figure 2). ${ }^{4}$ The chromophore is believed to be derived biogenetically by oxidative cyclisation of tetrahydropyrimidine amino acid residue $\mathbf{3}$, a proposal supported by incorporation studies with tyrosine and 2,4diaminobutyric acid, ${ }^{5}$ and by the co-occurrence of other related metabolites such as ferribactins, ${ }^{6}$ which lack the chromophore but contain the tyrosine-based tetrahydropyrimidine $\mathbf{3}$, isopyoverdins $\quad \mathbf{4}^{7}$ and the corresponding 5,6-dihydro metabolites 5 and $\mathbf{6}$ (Figure 3). ${ }^{8}$

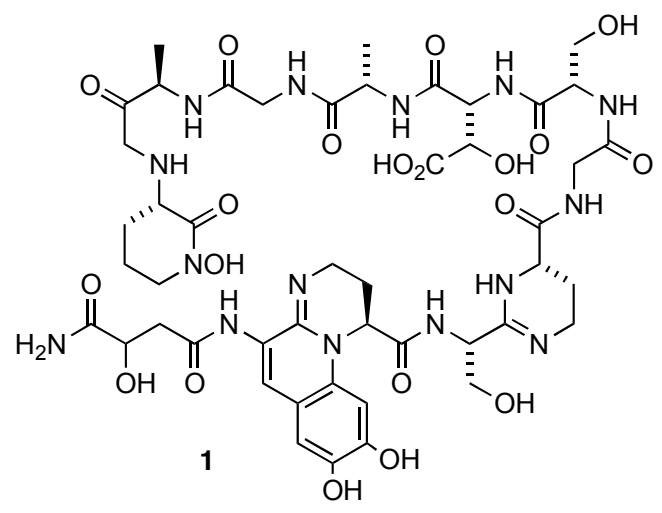

Figure 1. Structure of pyoverdin Pf CCM2798. In subsequent structures substituents on the chromophore are represented as R groups. 


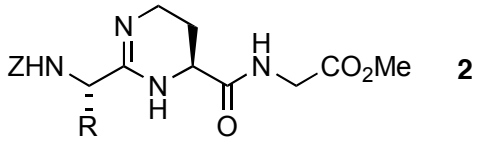

Figure 2. Tetrahydropyrimidine pseudodipeptides

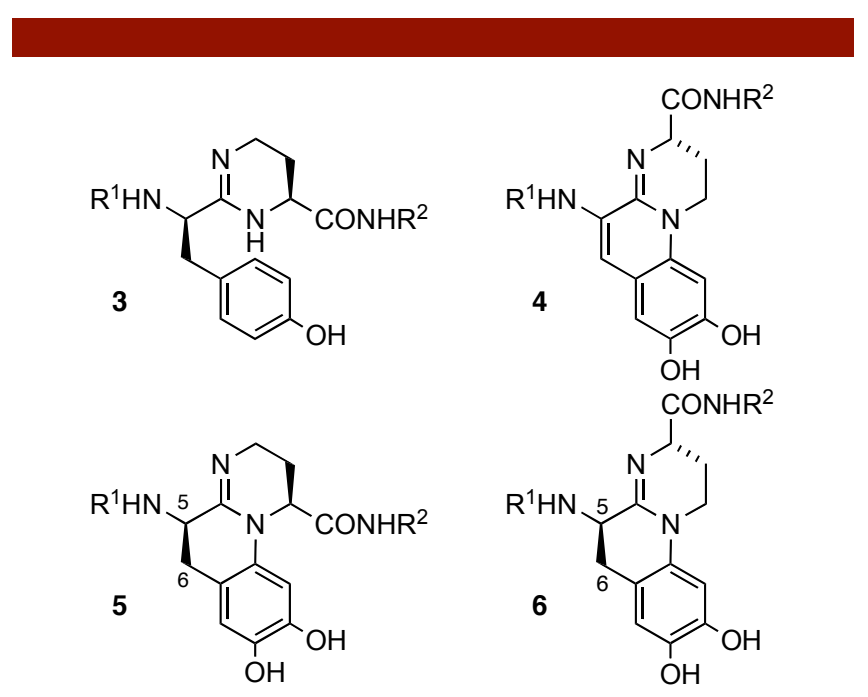

Figure 3. Co-metabolites biogenetically related to pyoverdins

The recent demonstration of enzymic oxidation of the simple analogue $\mathbf{7}$ of tetrahydropyrimidine $\mathbf{3}$ to form a model for the dihydropyrimido[1,2-a]quinoline chromophore, albeit in very low yield, ${ }^{9,10}$ prompts us to report here our biomimetic chemical synthesis of a model for the pyoverdin chromophore, and of homologues in the cyclic amidine ring, using phenolic oxidation by hypervalent iodine. ${ }^{11}$

The required substrates for oxidation were the phenolic cyclic amidines 7-9. These were all prepared from 2-(4hydroxyphenyl)propanoic acid $\mathbf{1 0}$ by the sequence outlined in Scheme 1. Treatment with benzyl bromide $\left(\mathrm{K}_{2} \mathrm{CO}_{3}\right.$, acetone reflux) and subsequent ester hydrolysis $(\mathrm{NaOH}$, $\mathrm{MeOH}$ aq) afforded the benzyl ether (98\%) which was converted into amide $\mathbf{1 1}$ via the acid chloride (oxalyl chloride, THF, DMF cat; $96 \%)$ and ammonolysis $\left(\mathrm{NH}_{3}\right.$ aq, $d 0.88$, THF; 76\%). After less reliable attempts at $O$ alkylation with Meerwein's salt, our preferred protocol for carboxamide activation was treatment with methyl trifluororomethanesulfonate $\left(\mathrm{CH}_{2} \mathrm{Cl}_{2}\right.$, reflux $)$ to afford the imidate salt 12 (we have also successfully employed $S$ alkylation of piperidine thioamides to achieve this carboxyl activation ${ }^{4}$ ). The crude imidate was treated directly with the appropriate diamine (EtOH, reflux) to form the required cyclic amidine. Thus 1,3-diaminopropane led to the tetrahydropyrimidine $\mathbf{1 3}(\mathrm{n}=1)(83 \%)^{12}$ as its

Scheme 1. Synthesis of cyclic amidine oxidation substrates
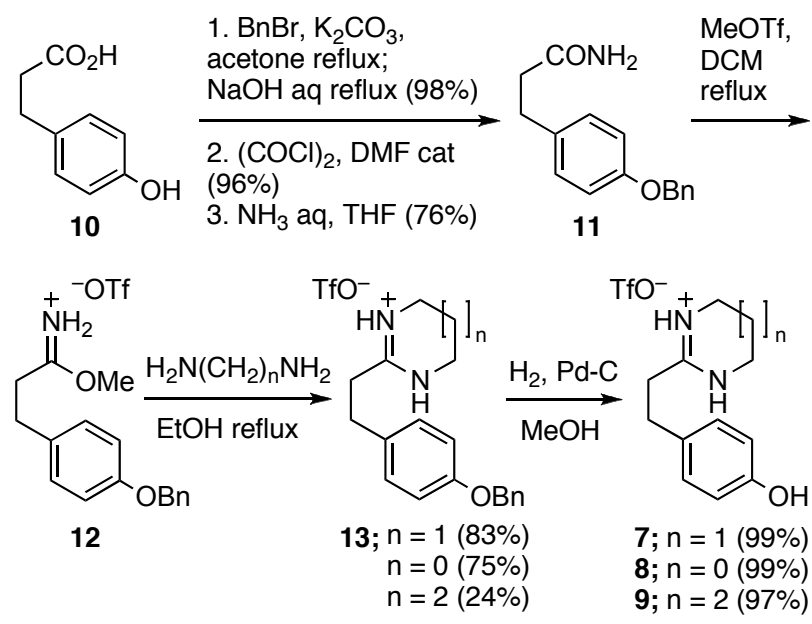

trifluoromethanesulfonate salt which was debenzylated by hydrogenolysis (Pd-C, 1 atm $\mathrm{H}_{2}$, EtOH) to afford oxidation substrate 7 (99\%). Likewise, reaction of 12 with 1,2diaminoethane or 1,4-diaminobutane, and subsequent hydrogenolysis, led to the corresponding imidazoline 8 (75 and $99 \%)^{12}$ and 1,3-diazepine 9 (24 and 97\%), respectively, again as the trifluoromethanesulfonate salts.

Oxidative cyclisation of tetrahydropyrimidine 7 to the pyoverdin chromophore ring system requires closure via a nitrogen atom. Our own studies and the work of others have clearly demonstrated that primary amides such as $\mathbf{1 1}$ or the corresponding piperidine amides cyclise via the carbonyl oxygen atom on iodine(III) oxidation. ${ }^{13}$ Ring closure via nitrogen has been demonstrated for acyl hydrazides, ${ }^{14}$ sulfonamides, ${ }^{15}$ or cyclic imidates (oxazines, dihydrooxazoles) although in the latter case the imidate then undergoes cleavage. ${ }^{16}$ Since our initial attempts at direct oxidative cyclisation of the cyclic amidines 7-9 were unpromising, we elected to oxidize in the presence of nucleophilic alcohol solvents. ${ }^{17}$ Thus treatment of tetrahydropyrimidine $\quad 7 \quad$ with bis(trifluoroacetoxy)iodobenzene (BTIB) in $\mathrm{MeOH}\left(20{ }^{\circ} \mathrm{C}\right.$, $5 \mathrm{~min}$ ) afforded a dienone intermediate 14a (Table 1) that could not be fully characterised but when chromatographed on basic alumina afforded tetrahydropyrimidoquinolinone trifluoromethanesulfonate 15a $(46 \%)$ as product of the desired oxidative cyclisation through a nitrogen atom. ${ }^{18}$ It is apparent that the intramolecular conjugate addition is alumina-mediated; indeed, stirring the dienone in solution with alumina also led to cyclisation, but chromatographic conversion was the more efficient protocol. When the BTIB oxidation and alumina treatment sequence was repeated with $\mathrm{EtOH}$ as oxidation solvent, the corresponding 
Table 1. Oxidative cyclisation of pyrimidine 7

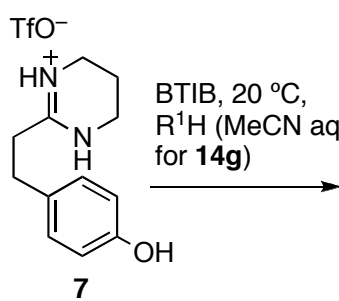

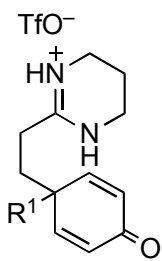

$( \pm)-14 a-g$

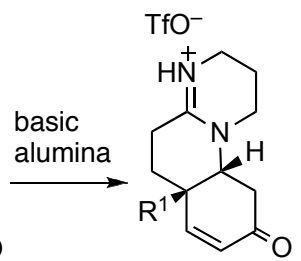

(土)-15a,b,f,g

\begin{tabular}{|l|l|l|l|}
\hline Entry & $\mathrm{R}^{1}$ & $\begin{array}{l}( \pm) \text {-Dienone salt } \\
\mathbf{1 4}^{\mathrm{a}}\end{array}$ & $\begin{array}{l}( \pm) \text {-Pyrimidoquinolinone } \\
\text { salt 15 (Yield \%) }\end{array}$ \\
\hline 1 & $\mathrm{OMe}$ & $\mathbf{1 4 a}$ & $\mathbf{1 5 a}(46 \%)$ \\
\hline 2 & $\mathrm{OEt}$ & $\mathbf{1 4 b}$ & $\mathbf{1 5 b}(34 \%)$ \\
\hline 3 & $\mathrm{OCHMe}_{2}$ & $\mathbf{1 4 c}$ & - \\
\hline 4 & $\mathrm{OCMe}_{3}$ & $\mathbf{1 4 d}$ & - \\
\hline 5 & $\mathrm{OCH}_{2} \mathrm{Ph}$ & $\mathbf{1 4 e}$ & - \\
\hline 6 & $\mathrm{NHCOMe}$ & $\mathbf{1 4 f}$ & $\mathbf{1 5 f}(41 \%)$ \\
\hline 7 & $\mathrm{OH}$ & $\mathbf{1 4 g}$ & $\mathbf{1 5 g}(4 \%)$ \\
\hline
\end{tabular}

${ }^{a}$ Dienones 14 were not fully characterized.

afforded dienones 14c-e that were not completely characterized. From an oxidation in moist acetonitrile, the cyclisation product $\mathbf{1 5 f}$ was isolated (41\%) via acetamide adduct 14f, and the hydroxyl adduct 15g was observed in low yield (approx. 4\%) from a reaction in water, via 14g. The structures of the methoxy-derivative 15a and ethoxy-derivative $\mathbf{1 5 b}$ were confirmed by X-ray crystallographic analysis which also revealed cis-6,6-ring fusion in the crystalline material. ${ }^{19,20}$

Aromatisation of the carbocyclic ring by elimination of alcohol from 15a,b under acidic conditions was more difficult than originally anticipated, presumably because the quinolinones were already protonated at the amidine function, hindering alkoxy-group protonation.

Scheme 2. Completion of the tetrahydropyrimidoquinolines<smiles>[R7][C@]12C=CC(=O)C[C@H]1N1CCC[NH+]=C1CC2</smiles>

$( \pm)-15 a ; R^{1}=O M e$ (土)-15b; $R^{1}=$ OEt

DDQ, 1,4-dioxan reflux (17a 38\%; 17b 10\%)
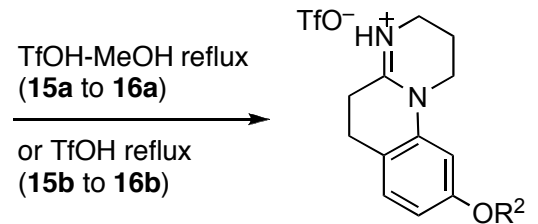

$16 \mathbf{a} ; R^{2}=\operatorname{Me}(57 \%)$ $16 b ; R^{2}=H(38 \%)$

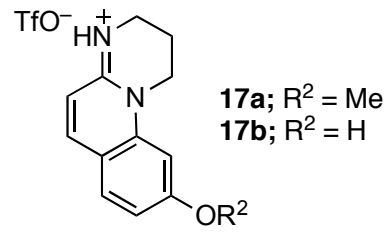

Treatment of 15a with trifluoromethanesulfonic acid afforded a mixture of the methoxy- and hydroxytetrahydropyrimidoquinoline salts 16a and 16b. We propose that $O$-alkylation arises by formation of the methylating agent methyl trifluoromethanesulfonate from the eliminated methanol in the reaction medium. In support of this, addition of $\mathrm{MeOH}$ to the acidic reaction medium afforded methyl ether 16a as major product (57\%) (Scheme 2). In contrast elimination from ethoxy compound 15b afforded solely the phenolic dihydropyrimidinoquinoline 16b (38\%), as presumably any ethyl trifluoromethanesulfonate formed is either less effective as an alkylating agent, or undergoes elimination. The structure of methyl ether 16a was confirmed by an Xray crystal structure. ${ }^{19}$ Completion of the pyoverdin chromophore model was achieved by dehydrogenation of 16a using DDQ (1,4-dioxane, reflux) to afford tricyclic salt 17a (38\%), purified by reverse-phase HPLC; the structure of 17a was also confirmed by a crystal structure determination. Dehydrogenation of $\mathbf{1 6} \mathbf{b}$ could also be achieved in low yield (10\%) to give a highly polar product 17b that was not fully characterized. These dehydrogenations could also be achieved on silica by microwave irradiation, but gave less pure products.

The oxidative cyclisation sequence was also performed on the imidazoline 8 and 1,3-diazepine 9 (Scheme 3). Thus BTIB oxidation using $\mathrm{MeOH}$ or $\mathrm{EtOH}$ as solvent, and subsequent alumina chromatography, afforded reduced imidazoquinolinone trifluoromethanesufonates

Scheme 3. Oxidative cyclisations of imidazoline 8, diazepine 9 

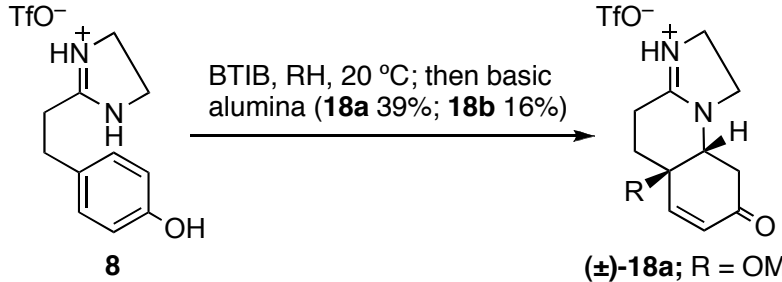

( \pm -18a; $\mathrm{R}=\mathrm{OMe}$ $( \pm)-18 b ; R=O E t$

$\mathrm{TfO}^{-}$
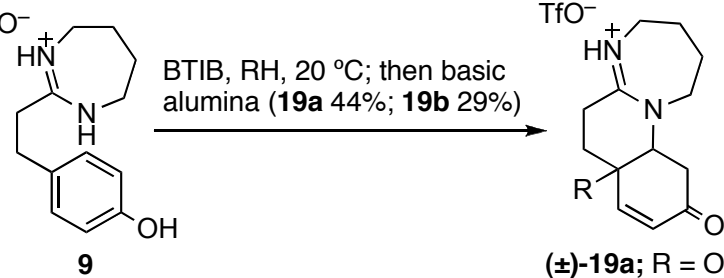

(土)-19a; $\mathrm{R}=\mathrm{OMe}$ $( \pm)-19 b ; R=$ OEt

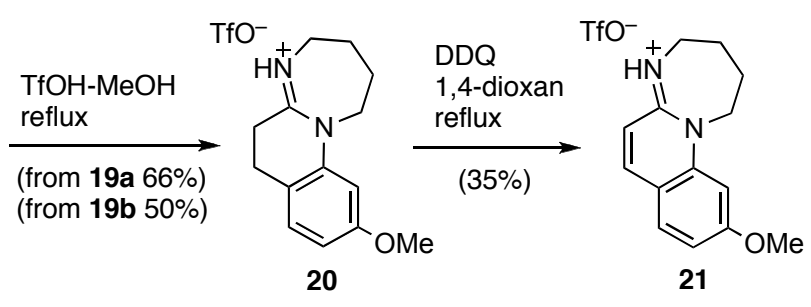

18a and 18b from imidazoline 8 (39\% and $16 \%$, respectively). Diazepine 9 similarly afforded the reduced alkoxyazepinoquinolinone salts 19a and 19b (44\% and $29 \%$, respectively). Intermediates $\mathbf{1 8}$ have not been taken further, but treatment of both 19a and 19b in trifluoromethanesulfonic acid-MeOH gave the methoxyhexahydroazepinoquinoline salt $20(66 \%$ and $50 \%$, respectively). DDQ dehydrogenation of $\mathbf{2 0}$ as previously led to the homologue $\mathbf{2 1}$ of the pyoverdin chromophore model (35\%).

The dihydropyrimidoquinoline 17a showed strong fluorescence, ${ }^{21}$ as do the natural pyoverdins; the sevenring analogue 21 showed a much weaker fluorescence (approx. $25 \%$ of that of 17a). The UV spectra of chromophores $\mathbf{1 7}$ and $\mathbf{2 1}$ compared acceptably with those of the natural pyoverdins, ${ }^{22}$ recognising that they have an incomplete substituent set.

We have thus chemically generated models for the dihydropyrimido[1,2- $a$ ]quinoline chromophore of the pyoverdin siderophores via a biomimetic route involving oxidative cyclisation. Efforts continue towards synthesis of the pyoverdins.

Acknowledgment. We acknowledge the financial support of Loughborough University (S. C. Y.), the Open University (J. D.) and EPSRC (J. E. S.), and the EPSRC National Crystallography Service at Southampton for the structure determination of $\mathbf{1 5 a}$.

Supporting Information Available: Procedures and spectral data for the synthesis of 7-9 and oxidative cyclisations to $17 \mathbf{a}, \mathbf{1 6 b}, \mathbf{1 8 a}, \mathbf{2 1}$; X-ray crystal data including CIF files for 15a, 15b, 16a and 17a. This material is available free of charge via the Internet at http://pubs.acs.org.

1. Fuchs, R.; Budziekewicz, H. Curr. Org. Chem. 2001, 5, 265288.Budziekewicz, H. FEMS Microbiol. Rev. 1993, 104, 209-228.

2. Demange, P.; Bateman, A.; Macleod, J. K.; Dell, A.; Abdallah, M. A. Tetrahedron Lett. 1990, 31, 7611-7614.

3. Jones, R. C. F.; Dickson, J. J. Peptide Sci. 2001, 42, 220-223, and refs. therein; Jones, R. C. F.; Gilbert, I. H.; Rees, D. C.; Crockett, A. K. Tetrahedron 1995, 51, 6315-6336.

4. Jones, R. C. F.; Crockett, A. K. Tetrahedron Lett. 1993, 34, 74597462.

5. Thompson, B. N.; Gould, S. J. Tetrahedron 1994, 50, 9865-9872; Böckmann, M.; Taraz, K.; Budziekewicz, K. Z. Naturforsch., C: Biosci. 1997, 52, 319-324.

6. Hohlneicher, U.; Hartmann, R.; Taraz, K.; Budziekewicz, H. Z Naturforsch. 1995, 50C, 337-344.

7. Jacques, Ph.; Ongena, M.; Gwose, I.; Seinsche, D.; Schröder, H.; Delfosse, Ph.; Thonart, Ph.; Taraz, K.; Budziekewicz, H. Z. Naturforsch. 1995, 50C, 622-629.

8. Gwose, I.; Taraz, K. Z. Naturforsch. 1992, 47C, 487-502. Michalke, R.; Taraz, K.; Budziekewicz, H.; Thonart, Ph.; Jacques, Ph. Z. Naturforsch. 1995, 50C, 855-857.

9. Dorrestein, P. C.; Poole, K.; Begley, T. P. Org. Lett. 2003, 5, 2215-2217.

10. Routes to cyclic amidine [1,2- $a]$-fused quinolines have also been reported by closure of the amidine ring as the final step using conventional or electrochemical protocols. See, for example: Jones, R. C. F.; Smallridge, M. J.; Chapleo, C. B. J. Chem. Soc., Perkin Trans. 1 1990, 385-391. Okimoto, M.; Yoshida, T.; Hoshi, M.; Hattori, K.; Komata, M.; Numata, K.; Tomozawa K. Aust. J. Chem. 2007, 60, 236242.

11. Wirth, T. Angew. Chem. Int. Ed. Engl. 2005, 44, 3656-3665. Wirth, T. Hypervalent Iodine Chemistry: Modern Developments in Organic Synthesis; Wirth, T., Ed.; Springer: Berlin, Germany, 2003; Vol. 224, pp 185-208. Tohma, H.; Kita, Y. idem, pp 209-248.

12. Some recovered amide $\mathbf{1 1}$ was isolated along with tetrahydropyrimidine $\mathbf{1 3}(\mathrm{n}=1)$ and imidazoline $\mathbf{1 3}(\mathrm{n}=0)(15$ and $4 \%$, respectively).

13. Smith, J. E. M.Phil. Thesis, The Open University, 2004. Kita, Y.; Tohma, H.; Kikuchi, K.; Inagaki, M.; Yakura, T. J. Org. Chem. 1991, $56,435-438$.

14. Clemente, D.-T. V.; Lobo, A. M.; Prabhakar, S. Tetrahedron Lett. 1994, 35, 2043-2046.

15. Ciufolini, M. A.; Canesi, S.; Ousmer, M.; Braun, N. A. Tetrahedron 2006, 62, 5318-5337.

16. Braun, N. A.; Bray, J. D.; Ousmer, M.; Peters, K.; Peters, E. M.; Bouchou, D.; Ciufolini, M. A. J. Org. Chem. 2000, 65, 4397-4408.

17. Tohma, H.; Morioka, H.; Takizawa, S.; Yarisawa, M.; Kita, Y. Tetrahedron 2001, 57, 345-352, and refs. therein.

18. Pouysegu, L.; Avella, A.-V.; Quideau, S. J. Org. Chem., 2002 61, 3425-3436, and refs. therein. Cf. Wipf, P.; Methot, J.-L. Org. Lett., 2000, 2,4213

19. Crystal structures of $\mathbf{1 5 a}, \mathbf{1 5} \mathbf{b}, \mathbf{1 6} \mathbf{a}$ and $\mathbf{1 7} \mathbf{a}$ were refined to convergence with $R$ factors of $0.061,0.054,0.042$ and 0.097 , respectively. Full details are presented in the Supporting Information.

20. A cis-ring junction is expected from attack of the amidine onto the dienone from the face opposite the alkoxy group.

21. 17a: fluorescence em $\left(\mathrm{MeOH}-\mathrm{H}_{2} \mathrm{O} 1: 1 \mathrm{v} / \mathrm{v}, \mathrm{pH} 6.5\right.$, ex 338, 353, $\left.\lambda_{\max }\right) 372\left(\varepsilon 5.09 \times 10^{6}\right)$ and $382\left(4.80 \times 10^{6}\right)$, respectively; UV-vis $\left(\mathrm{MeOH}-\mathrm{H}_{2} \mathrm{O} 1: 1 \mathrm{v} / \mathrm{v}, \mathrm{pH} 6.5, \lambda\right) 219\left(\varepsilon 6.3 \times 10^{4}\right), 338\left(2.3 \times 10^{4}\right)$ and $353\left(2.0 \times 10^{4}\right)$. No significant change over $\mathrm{pH}$ range 6.5-9.

22. For example: Demange, P.; Wendenbaum, S.; Linget, C.; Mertz, C.; Cung, M. T.; Dell, A.; Abdallah, M. A. Biol. Met. 1990, 3, 155-170. For pyoverdin Pa from Pseudomonas aeruginosa ATCC 15692: UV-vis $(\mathrm{pH} 4.2, \lambda) 365 \mathrm{~nm}\left(\varepsilon 1.4 \times 10^{4}\right)$ and $380\left(1.4 \times 10^{4}\right)$. 